\title{
Age-of-acquisition and subjective frequency estimates for all generally known monosyllabic French words and their relation with other psycholinguistic variables
}

\author{
Ludovic Ferrand, Patrick Bonin, Alain Méot, and Maria Augustinova \\ CNRS and Université Blaise Pascal, Clermont-Ferrand, France \\ BORIS NEW \\ CNRS and Université Paris Descartes, Paris, France \\ Christophe Pallier \\ INSERM and Service Hospitalier Frédéric Joliot, Paris, France \\ AND \\ MARC BRYSBAERT \\ Royal Holloway, University of London, London, England
}

\begin{abstract}
Ratings for age of acquisition (AoA) and subjective frequency were collected for the 1,493 monosyllabic French words that were most known to French students. AoA ratings were collected by asking participants to estimate in years the age at which they learned each word. Subjective frequency ratings were collected on a 7-point scale, ranging from never encountered to encountered several times daily. The results were analyzed to address the relationship between AoA and subjective frequency ratings with other psycholinguistic variables (objective frequency, imageability, number of letters, and number of orthographic neighbors). The results showed high reliability ratings with other databases. Supplementary materials for this study may be downloaded from the Psychonomic Society's Archive of Norms, Stimuli, and Data, www.psychonomic.org/archive.
\end{abstract}

Visual word recognition is a fast, efficient, and relatively effortless cognitive skill in adults. These aspects of performance obscure the complexity of the processes involved in this behavior, but previous studies have identified a number of relevant variables that affect the speed and accuracy with which words can be processed (e.g., Balota, Cortese, Sergent-Marshall, Spieler, \& Yap, 2004; Balota, Yap, \& Cortese, 2006). Most of these variables (such as printed frequency, number of letters, number of phonemes, orthographic neighborhood, and regularity) are objective and are based on large corpora of words (e.g., CELEX for English and Dutch - Baayen, Piepenbrock, \& van Rijn, 1993; Lexique for French-New, Pallier, Brysbaert, \& Ferrand, 2004). However, other variables, such as age of acquisition (AoA), subjective frequency, and imageability, are subjective and have to be collected by asking participants to rate the stimuli. Because collecting such data is time consuming, it is good practice to make these ratings available so that other researchers can share them.

In recent years, norms have become available for large numbers of English words (more than 1,000) for the following subjective variables: AoA (Bird, Franklin, \& Howard, 2001; Cortese \& Khanna, 2008; StadthagenGonzalez \& Davis, 2006), subjective frequency (Balota, Pilotti, \& Cortese, 2001), and imageability (Bird et al., 2001; Cortese \& Fugett, 2004; Stadthagen-Gonzalez \& Davis, 2006). Similar norms have been collected for AoA in Dutch (Ghyselinck, De Moor, \& Brysbaert, 2000) and Portuguese (Marques, Fonseca, Morais, \& Pinto, 2007). In French, there have been a few published norming studies for AoA (Alario \& Ferrand, 1999; Bonin, Méot, et al., 2003; Bonin, Peereman, Malardier, Méot, \& Chalard, 2003; Ferrand, Grainger, \& New, 2003) and subjective frequency (Bonin, Méot, et al., 2003; Bonin, Peereman, et al., 2003; Flieller \& Tournois, 1994), but all of them were limited to a reasonably small number of stimuli that were used in a typical line of research.

Norms are particularly interesting when they are available for a complete group of stimuli (rather than for a selected subsample). In that case, they can be used in the multiple regression analyses on unselected stimulus samples that are currently becoming important (see in particu-

L. Ferrand, ludovic.ferrand@univ-bpclermont.fr 
lar the work by Balota; e.g., Balota et al., 2004; see also Baayen, Feldman, \& Schreuder, 2006). The motivation of the present study was to provide AoA and subjective frequency ratings for the most generally known French monosyllabic words (for a total of 1,493; see below for more details). Much research on visual word recognition is done with monosyllabic words (e.g., Coltheart, Rastle, Perry, Langdon, \& Ziegler, 2001; Harm \& Seidenberg, 2004; Perry, Ziegler, \& Zorzi, 2007; Seidenberg \& McClelland, 1989), and, therefore, these ratings are needed most. However, we made an effort to include not only nouns, but also verbs, adjectives, adverbs, numerals, and function words.

AoA refers to the age at which a word was learned (see, e.g., Gilhooly \& Logie, 1980). This measure can be obtained by asking adults to estimate this age (subjective AoA; Morrison \& Ellis, 1995) or by the analysis of children's production (objective AoA; Morrison, Chappell, \& Ellis, 1997). Both methods have been found to produce similar estimates (Chalard, Bonin, Méot, Boyer, \& Fayol, 2003; Morrison et al., 1997). A large number of studies have shown systematically that words acquired early in life are processed faster and more accurately than words acquired later in life (see Johnston \& Barry, 2006, and Juhasz, 2005, for recent reviews). The AoA effect has been found in many different tasks (e.g., object, face, and action naming; word naming; and lexical decision) and in different populations (e.g., children, young and old adults, or aphasics), although there still is much discussion of the extent to which AoA is a genuine variable or can be explained on the basis of cumulative frequency measures and/or differences in frequency trajectory (Bonin, Barry, Méot, \& Chalard, 2004; Cortese \& Khanna, 2007; Zevin \& Seidenberg, 2002, 2004).

Subjective frequency, the other subjective variable estimated in the present study, is considered a measure of the frequency of exposure to a word. Gernsbacher (1984) suggested that subjective familiarity is a better predictor of word performance than is objective word frequency, especially for low-frequency words. However, Balota et al. (2001) suggested that the subjective familiarity ratings collected by Gernsbacher included semantic and/or orthographic/phonological components. Therefore, they used different instructions for their subjective frequency ratings, which we replicate here. These instructions minimize the potential influence of additional sources of information. Thus, participants had to rate words on a relatively neutral, 7-point frequency-of-exposure scale (with $1=$ never encountered, $2=$ once a year, $3=$ once $a$ month, $4=$ once a week, $5=$ once every two days, $6=$ once a day, $7=$ several times a day). Subjective frequency measures are important in assessing the extent to which objective frequency measures capture the full processing differences due to the amount of exposure; they play an increasingly important role in research related to the AoAversus-frequency debate. Balota et al. (2001) investigated the relationship between objective frequency and subjective frequency of encounter estimates for a megastudy of lexical decision performance (including 2,928 monosyllabic English words; see also Balota et al., 2004); they showed that subjective frequency estimates were a slightly better predictor of lexical decision times than were the available objective frequency measures.

\section{METHOD}

\section{Participants}

Fifty-nine psychology students from the Université Blaise Pascal, Clermont-Ferrand, France, participated in this study-28 in the subjective frequency task and 31 in the AoA task. The participants (10 male and 49 female; mean age 21.3 years, range $18-33$ years) were all native speakers of French and received $€ 25$ for their participation.

\section{The Word Corpus}

All French monosyllabic word forms were extracted from Lexique 2 (New et al., 2004) and Lexique 3 (New, Brysbaert, Veronis, $\&$ Pallier, 2007), which are based on very large corpora of contemporary French texts and film subtitles. From this sample, we excluded the words we would never use as targets in word recognition experiments (such as words we never use, loan words from English, sexually charged words, and abbreviations) and all polymorphemic words (in particular plurals and verb inflections other than the infinitive form). Next, we presented words to a group of 35 students and excluded those words that more than $67 \%$ of the students indicated they did not know. The remaining sample consisted of 1,493 words. For each word, printed frequency, number of letters, number of phonemes, and number of orthographic neighbors were taken from Lexique 3 (New et al., 2007). Imageability ratings were taken from Bonin, Ferrand, Méot, and Roux (2008). Table 1 lists the descriptive statistics for these variables.

\section{Procedure}

Ratings were collected via microcomputers in a computer lab in two sessions held 1 week apart. Each task was run using PsyScope 1.2.5 on an Apple Power Mac computer. Each session lasted about $1 \mathrm{~h}$. In one block, 746 words were rated, and in the other, the remaining 747 . The order of the words presented in each block was counterbalanced across the participants. Within the blocks, the order of items was random for each participant.

For both tasks, a fixation point was presented on each trial at the center of the screen for $500 \mathrm{msec}$, immediately followed by a word that was presented in lowercase (48-point, Chicago font) and remained on the screen until the participant's response. The next trial was initiated $3 \mathrm{sec}$ later.

For the subjective frequency task, a 1-7 scale was presented at the bottom of the screen. Raters of subjective frequency were asked to provide ratings using the 7-point scale used by Balota et al. (2001), with 1 assigned to words they never encountered, $2=$ once a year, $3=$ once a month, $4=$ once a week, $5=$ once every two days, $6=$ once $a$ day, $7=$ several times $a$ day. The rating was entered via the keyboard. The instructions employed in this task were similar to those used by Balota et al. (2001):

Throughout our lives, we hear and see many words. These words differ in how commonly or frequently they have been encoun-

Table 1

Summary Statistics for 1,493 French Words

\begin{tabular}{lrrc}
\hline \multicolumn{1}{c}{ Variable } & \multicolumn{1}{c}{$M$} & \multicolumn{1}{c}{$S D$} & \multicolumn{1}{c}{ Range } \\
\hline Subjective frequency & 4.24 & 1.04 & $2.32-7$ \\
AoA & 7.79 & 2.35 & $2.81-15.45$ \\
Printed frequency $^{\mathrm{a}}$ & 301.71 & $1,801.69$ & $0-38,943.65$ \\
Letters $^{\mathrm{a}}$ & 4.72 & 1.12 & $2-8$ \\
Phonemes $^{\mathrm{a}}$ & 3.49 & 1.08 & $1-7$ \\
Neighbors $^{\mathrm{a}}$ & 6.52 & 4.94 & $0-24$ \\
Imageability $^{\mathrm{b}}$ & 4.54 & 1.55 & $1.06-6.93$ \\
\hline
\end{tabular}

aTaken from Lexique 3; New et al. (2007). bTaken from Bonin et al. (2008); on a 7-point scale. 
Table 2

Correlations of the Present Subjective Age of Acquisition (AoA) Measures With Those Provided by Other Databases

Correlation

With the

Present Study

\begin{tabular}{llrr}
\cline { 3 - 4 } \multicolumn{1}{c}{ Language } & \multicolumn{1}{c}{ Study } & $r$ & \multicolumn{1}{c}{$N$} \\
\cline { 2 - 4 } French & Alario \& Ferrand (1999) & .91 & 113 \\
French & Bonin, Peereman, et al. (2003) & .88 & 99 \\
French & Chalard et al. (2003)* & .64 & 78 \\
French & Ferrand et al. (2003) & .95 & 310 \\
Canadian French & Sirois et al. (2006) & .88 & 81 \\
American English & $\begin{array}{l}\text { Cortese \& Khanna (2008) } \\
\text { British English }\end{array}$ & $\begin{array}{l}\text { Stadthagen-Gonzalez \& Davis } \\
\text { (2006) }\end{array}$ & 653 \\
& & .69 & 243 \\
\hline
\end{tabular}

Note-All correlations are significant at the $p<.0001$ level. $\quad$ *Objective AoA.

tered. Some words are encountered very frequently, whereas other words are encountered infrequently. The purpose of this study is to determine, according to your estimation, the frequency of the words you encounter in their written or spoken form. You should base your frequency ratings according to the following 7 -point scale: $1=$ never, $2=$ once $a$ year, $3=$ once $a$ month, $4=$ once a week, $5=$ every two days, $6=$ once $a$ day, $7=$ several times a day. Your task is to type your estimation on the keyboard. For instance, if you think that you never encountered a word, you type 1. Or, if you think that you encounter the word "detergent" once a week, type 4 . If you think that you encounter the word "bread" several times a day, type 7. When making your ratings, try to be as accurate as possible, but do not spend too much time on any one word. If you have any question, ask the experimenter now. Otherwise, press $<$ Enter $>$ to begin the study.

For the AoA task, participants were asked to type (on the keyboard) below each word an estimate, in years, of when they learned the word (following Ghyselinck et al., 2000, procedure; see also Stadthagen-Gonzalez \& Davis, 2006). The instructions employed in this task were similar to those used by Stadthagen-Gonzalez and Davis:

We acquire words throughout our lives. Some words are acquired at a very early stage, some are acquired later, and others fall in between. The purpose of this study is to determine the approximate age at which words have been acquired (in their written or spoken form). By "learning a word" we mean when you understood that word when somebody used it in front of you, even if you did not use, read, or write it at that time. Your task is to type, in years, the age at which you learned each of the words presented on the screen. An approximate age is good enough for this rating. For instance, if you think you learned the word "dragon" at the age of 3 years, then you type 3 below this word. If you think you learned the word "tax" at the age of 16 , then type 16 . If you do not know the meaning of a word, type an $\mathrm{N}$ below the word. When making your ratings, try to be as accurate as possible, but do not spend too much time on any one word. If you have any question, ask the experimenter now. Otherwise, press $<$ Enter $>$ to begin the study.

We used this AoA measure rather than the 7-point scale used by Gilhooly and Logie (1980), because participants find the instruction easier to follow and because it gives more precise information (e.g., for calculating the variable "years known," defined as the difference between the current age and the AoA).

In both tasks, reaction times to the ratings were measured, although the participants were not informed of this and were not instructed to respond as quickly as possible. Following Cortese and Fugett (2004), the primary purpose of recording reaction times was to allow us to eliminate ratings that were made prematurely.

\section{RESULTS}

Following Cortese and Khanna (2008), latencies and ratings were eliminated whenever a rating was made in less than $500 \mathrm{msec}$. The instructions included no guidelines with respect to speed, so no upper limit for response latencies was set. This criterion eliminated less than $2 \%$ of the data in both rating tasks. For the subjective frequency task, the average latency was $2,486 \mathrm{msec}(S D=$ $1,214)$, and for the AoA rating task, the average latency was $3,353 \mathrm{msec}(S D=915)$.

Mean AoA and subjective frequency ratings and their respective $S D$ s are presented in the full database in alphabetical order (Excel file). This database can be downloaded from ludovic.ferrand.googlepages.com/databases.

To assess the reliability of our ratings, we correlated them with other published norms.

For AoA (see Table 2), there were 113 words in common with Alario and Ferrand (1999), 99 in common with Bonin, Peereman, et al. (2003), 310 in common with Ferrand et al. (2003), 81 in common with Sirois, Kremin, and Cohen (2006), 653 in common with one-to-one translations of Cortese and Khanna (2008), and 243 in common with one-to-one translations of Stadthagen-Gonzalez and Davis (2006). Despite the fact that some studies were conducted in French, Canadian French, American English, or British English, all correlations were high (between .69 and .95). The correlation between our subjective AoA ratings and the objective AoA ratings reported by Chalard et al. (2003) for French was somewhat lower $(r=.64, N=$ 78 ), but was still very acceptable.

Figure 1 shows the distribution of items' estimated AoA. In order to test the reliability, we split the participants into two groups and computed the correlation between the averaged estimated AoA by item. Doing this a thousand times with different subgroups, we found that the split-half correlation ranged from .95 to $.97(M=.96)$.

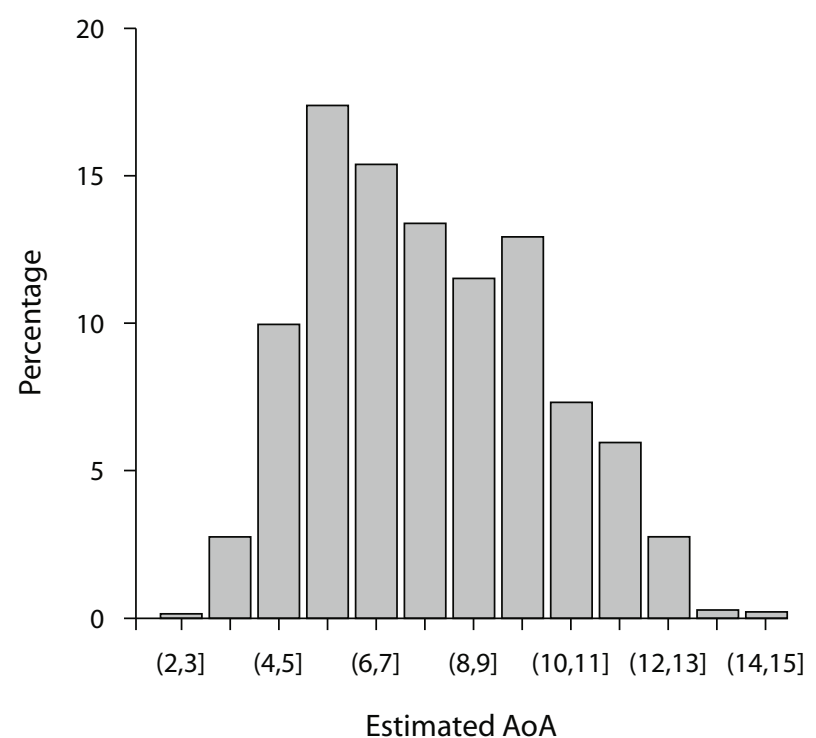

Figure 1. Distribution of age of acquisition (AoA), by items. 
For subjective frequency (see Table 3), there were 277 words in common with Bonin, Méot, et al. (2003), 360 in common with Desrochers and Bergeron (2000), 111 in common with Flieller and Tournois (1994), 681 in common with one-to-one translations of Balota et al. (2001), and 243 in common with one-to-one translations of Stadthagen-Gonzalez and Davis (2006). The first three studies were conducted in French (one in Canadian French) and the other two were conducted in English (American and British English). Despite these differences, the correlations were high (between .70 and .87; see Table 3 ).

Figure 2 shows the relationship between subjective frequencies and the lexical (form) frequencies provided by the film subtitle database of Lexique 3. Pearson's correlation between the two variables is .81. In 1,000 simulations, splitting the participants into two groups, the splithalf correlation of the averaged subjective frequencies ranged from .89 to $.95(M=.93)$.

Overall, these correlations (in both tasks) provide evidence for congruent validity. As in Cortese and Khanna (2007, 2008), our large-scale study with 1,493 words provided subjective frequency ratings and AoA ratings similar to smaller studies with fewer trials. Therefore, the length of the testing sessions did not negatively affect participants' ratings, had already been shown in other published megastudies (e.g., Balota et al., 2004; Cortese \& Fugett, 2004; Cortese \& Khanna, 2007, 2008).

Table 3

Correlations of the Present Subjective Frequency Measures With Those Provided by Other Databases for Common Items

\begin{tabular}{llcc}
\hline Language & \multicolumn{1}{c}{ Study } & \multicolumn{2}{c}{$\begin{array}{c}\text { Correlation } \\
\text { With the } \\
\text { Present Study }\end{array}$} \\
\cline { 2 - 4 } French & Bonin, Méot, et al. (2003) & .87 & 277 \\
Canadian French & Desrochers \& Bergeron (2000) & .73 & 360 \\
French & Flieller \& Tournois (1994) & .86 & 111 \\
American English & Balota et al. (2001) & .78 & 681 \\
British English & Stadthagen-Gonzalez \& Davis & & \\
& $(2006)$ & .70 & 243 \\
\hline
\end{tabular}

Note-All correlations are significant at the $p<.0001$ level.

Table 4

Correlations Between Age of Acquisition (AoA), Subjective Frequency, and Other Lexical Variables (Printed Frequency, Number of Letters, Number of Phonemes, Number of Orthographic Neighbors, and Imageability)

\begin{tabular}{lcc}
\hline \multicolumn{1}{c}{ Variable } & AoA & Subjective Frequency \\
\hline AoA & +1.00 & -.57 \\
Subjective frequency & -.57 & +1.00 \\
$\log _{10}$ (Lexique 3 written +1$)$ & -.60 & +.73 \\
$\log _{10}$ (Lexique 3 spoken +1$)$ & -.59 & +.81 \\
$\log _{10}$ (MANULEX + 1) & -.75 & +.73 \\
Letters & +.20 & -.28 \\
Phonemes & +.28 & -.26 \\
Neighbors & -.22 & +.23 \\
Imageability & -.32 & -.28 \\
\hline
\end{tabular}

Note-Lexique 3 (from New et al., 2007); MANULEX (from Lété et al., 2004). All correlations are significant at the $p<.01$ level (bilateral).

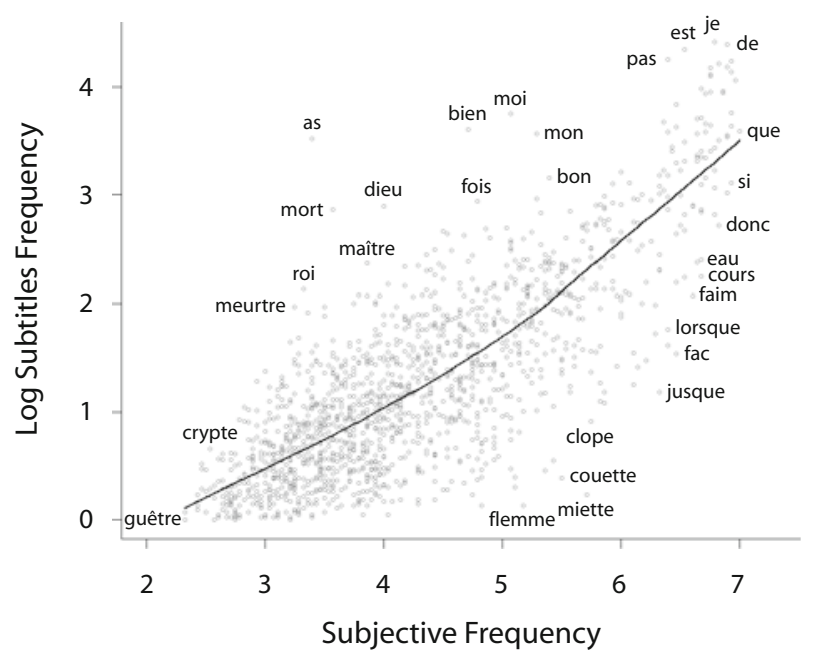

Figure 2. Relationship between subjective frequency and lexical frequencies estimated on the corpus of subtitles of the Lexique 3 database (each dot corresponds to a word). Some of the words having the maximal "discrepancy" between the two measures are displayed.

\section{Relation Between the Subjective Norms and Other Lexical Variables}

Table 4 shows the correlations between AoA and subjective frequency and a selection of lexical variables: word length (number of letters and number of phonemes), number of orthographic neighbors, a variety of measures of frequency (printed frequency/film frequency from Lexique 3, MANULEX-Lété, Sprenger-Charolles, \& Colé, 2004), and imageability. As can be seen, AoA is correlated significantly with all of these variables. The direction of these correlations is in agreement with expectations regarding the age at which words are acquired. Words that are acquired later tend to be less frequent (both subjectively and objectively), less imageable, and longer (with fewer orthographic neighbors) than words that are acquired earlier.

Subjective frequency is correlated significantly with AoA, printed frequency, length (both number of letters and number of phonemes), number of orthographic neighbors, and imageability. Thus, more (subjective) frequent words tend to be acquired earlier, are more objectively frequent, tend to be shorter, are less imageable, and have more orthographic neighbors than less (subjective) frequent words. As in previous studies (e.g., Balota et al., 2001; Stadthagen-Gonzalez \& Davis, 2006), there were strong correlations between subjective frequency and both written and spoken frequency, suggesting that subjective frequency reflects frequency of exposure.

In order to study the contribution of each of these variables, a simultaneous multiple regression analysis was conducted, with AoA as the dependent variable and with five independent variables (see Table 5). To avoid problems of multicollinearity among the independent variables, we used only a single measure of frequency (printed frequency from Lexique 3 ) and a single measure of length (number of letters). The overall regression equation was 
Table 5

Multiple-Regression Analysis With Rated AoA As the Dependent Variable and Five Independent Variables

\begin{tabular}{lcccc}
\hline Independent Variable & $\beta$ & $S E$ & $t$ & $p$ \\
\hline Imageability & -.528 & .016 & -33.398 & .001 \\
Subjective frequency & -.411 & .023 & -17.947 & .001 \\
Printed frequency & -.386 & .023 & -16.983 & .001 \\
Neighbors & -.100 & .017 & -5.729 & .001 \\
Letters & -.002 & .018 & -0.106 & .915 \\
\hline
\end{tabular}

Note-Printed frequency, $\log _{10}$ (Lexique $3+1$ ).

significant $[F(5,1487)=574.68, p<.0001, R=.812]$, and taken together, the predictor variables accounted for $66 \%$ of the variance. As can be seen in Table 5, four out of the five variables included in the regression made independent contributions to the predicted AoA rating, with the best predictors being imageability, subjective frequency, and printed frequency, followed by number of orthographic neighbors. As in Marques et al.'s (2007) study, the number of letters was not a significant predictor. These findings are consistent with previous studies of AoA on different sets of words (Bird et al., 2001; Gilhooly \& Logie, 1980; Marques et al., 2007; StadthagenGonzalez \& Davis, 2006).

\section{CONCLUSION}

We have collected AoA and subjective frequency norms for the most widely known monosyllabic French words, including nouns, verbs, adjectives, adverbs, numerals, and function words. This makes it possible to do all types of regression analyses on unselected word samples. In addition, researchers will no longer be restricted to a limited subset of possible stimuli if they want to match their stimuli on AoA and subjective frequency. The reliability of the data is demonstrated by the high correlations with previously published norms. This database should be useful for researchers interested in manipulating or controlling these factors in word-recognition, neuropsychological, or memory studies.

\section{AUTHOR NOTE}

This work was supported by ANR (Agence Nationale de la Recherche, France) Grant CORP-00101 to L.F. We thank Emmanuelle Neuville and Claire Rastoul for testing the participants and collecting the norms. Address correspondence regarding this article to L. Ferrand, CNRS and Université Blaise Pascal, Laboratoire de Psychologie Sociale et Cognitive (LAPSCO-UMR CNRS 6024), 34, Avenue Carnot, 63037 Clermont-Ferrand, France (e-mail: ludovic.ferrand@univ-bpclermont.fr).

\section{REFERENCES}

Alario, F.-X., \& Ferrand, L. (1999). A set of 400 pictures standardized for French: Norms for name agreement, image agreement, familiarity, visual complexity, image variability, and age of acquisition. Behavior Research Methods, Instruments, \& Computers, 31, 531-552.

BaAyen, R. H., Feldman, L. B., \& Schreuder, R. (2006). Morphological influences on the recognition of monosyllabic monomorphemic words. Journal of Memory \& Language, 55, 290-313.

Baayen, R. H., Piepenbrock, R., \& van Rijn, H. (1993). The CELEX Lexical Database (Release 1) [CD-ROM]. Philadelphia: Linguistic Data Consortium, University of Pennsylvania.

Balota, D. A., Cortese, M. J., Sergent-Marshall, S. D., Sieler,
D. H., \& YAP, M. J. (2004). Visual word recognition of single-syllable words. Journal of Experimental Psychology: General, 133, 283-316.

Balota, D. A., Pilotti, M., \& Cortese, M. J. (2001). Subjective frequency estimates for 2,938 monosyllabic words. Memory \& Cognition, 29, 639-647.

Balota, D. A., Yap, M. J., \& CoRtese, M. J. (2006). Visual word recognition: The journey from features to meaning (a travel update). In M. J. Traxler \& M. A. Gernsbacher (Eds.), Handbook of psycholinguistics (2nd ed., pp. 285-375). London: Academic Press.

Bird, H., Franklin, S., \& Howard, D. (2001). Age of acquisition and imageability ratings for a large set of words, including verbs and function words. Behavior Research Methods, Instruments, \& Computers, 33, 73-79.

Bonin, P., Barry, C., Méot, A., \& Chalard, M. (2004). The influence of age of acquisition in word reading and other tasks: A never ending story? Journal of Memory \& Language, 50, 456-476.

Bonin, P., Ferrand, L., MÉot, A., \& Roux, A. (2008). Imageability ratings for all generally known monosyllabic French words. Manuscript in preparation.

Bonin, P., Méot, A., Aubert, L., Malardier, N., Niedenthal, P., \& CAPElle-Toczek, M.-C. (2003). Normes de concrétude, de valeur d'imagerie, de fréquence subjective et de valence émotionnelle pour 866 mots [Concreteness, imageability, subjective frequency, and emotionality ratings for 866 words]. L'Année Psychologique, 103, 655-694.

Bonin, P., Peereman, R., Malardier, N., Méot, A., \& Chalard, M. (2003). A new set of 299 pictures for psycholinguistic studies: French norms for name agreement, image agreement, conceptual familiarity, visual complexity, image variability, age of acquisition, and naming latencies. Behavior Research Methods, Instruments, \& Computers, 35, 158-167.

Chalard, M., Bonin, P., Méot, A., Boyer, B., \& Fayol, M. (2003). Objective age-of-acquisition (AoA) norms for a set of 230 object names in French: Relationships with psycholinguistic variables, the English data from Morrison et al. (1997), and naming latencies. European Journal of Cognitive Psychology, 15, 209-245.

Coltheart, M., Rastle, K., Perry, C., Langdon, R., \& Ziegler, J. (2001). DRC: A dual route cascaded model of visual word recognition and reading aloud. Psychological Review, 108, 204-256.

Cortese, M. J., \& Fugett, A. (2004). Imageability ratings for 3,000 monosyllabic words. Behavior Research Methods, Instruments, \& Computers, 36, 384-387.

Cortese, M. J., \& Khanna, M. M. (2007). Age of acquisition predicts naming and lexical-decision performance above and beyond 22 other predictor variables: An analysis of 2,342 words. Quarterly Journal of Experimental Psychology, 60, 1072-1082.

Cortese, M. J., \& Khanna, M. M. (2008). Age of acquisition ratings for 3,000 monosyllabic words. Behavior Research Methods, 40, 791-794.

Desrochers, A., \& Bergeron, M. (2000). Valeurs de fréquence subjective et d'imagerie pour un échantillon de 1,916 substantifs de la langue française [Value of subjective frequency and imagery for a sample of 1,916 French language nouns]. Canadian Journal of Experimental Psychology, 54, 274-325.

Ferrand, L., Grainger, J., \& New, B. (2003). Normes d'âge d'acquisition pour 400 mots monosyllabiques [Age-of-acquisition norms for 400 monosyllabic French words]. L'Année Psychologique, 103, 445-467.

Flieller, A., \& Tournois, J. (1994). Imagery value, subjective and objective frequency, date of entry into the language, and degree of polysemy in a sample of 998 French words. International Journal of Psychology, 29, 471-509.

Gernsbacher, M. A. (1984). Resolving 20 years of inconsistent interactions between lexical familiarity and orthography, concreteness, and polysemy. Journal of Experimental Psychology: General, 113, 256-281.

Ghyselinck, M., De Moor, W., \& Brysbaert, M. (2000). Age-ofacquisition ratings for 2,816 Dutch four- and five-letter nouns. Psychologica Belgica, 40, 77-98.

Gilhooly, K. J., \& Logie, R. H. (1980). Age-of-acquisition, imagery, concreteness, familiarity, and ambiguity measures for 1,944 words. Behavior Research Methods \& Instrumentation, 12, 395-427.

Harm, M. W., \& Seidenberg, M. S. (2004). Computing the meanings of words in reading: Cooperative division of labor between visual and phonological processes. Psychological Review, 111, 662-720. 
Johnston, R. A., \& Barry, C. (2006). Age of acquisition and lexical processing. Visual Cognition, 13, 789-845.

Juhasz, B. J. (2005). Age-of-acquisition effects in word and picture identification. Psychological Bulletin, 131, 684-712.

Lété, B., Sprenger-Charolles, L., \& Colé, P. (2004). MANUlEX: A grade-level lexical database from French elementary school readers. Behavior Research Methods, Instruments, \& Computers, 36, 156-166.

Marques, J. F., Fonseca, F. L., Morais, A. S., \& Pinto, I. A. (2007). Estimated age of acquisition norms for 834 Portuguese nouns and their relation with other psycholinguistic variables. Behavior Research Methods, 39, 439-444.

Morrison, C. M., Chappell, T. D., \& Ellis, A. W. (1997). Age of acquisition norms for a large set of object names and their relation to adult estimates and other variables. Quarterly Journal of Experimental Psychology, 50A, 528-559.

Morrison, C. M., \& Ellis, A. W. (1995). Roles of word frequency and age of acquisition in word naming and lexical decision. Journal of Experimental Psychology: Learning, Memory, \& Cognition, 21, 116-133.

New, B., Brysbaert, M., Veronis, J., \& Pallier, C. (2007). The use of film subtitles to estimate word frequencies. Applied Psycholinguistics, 28, 661-677.

New, B., Pallier, C., Brysbaert, M., \& Ferrand, L. (2004). Lexique 2: A new French lexical database. Behavior Research Methods, Instruments, \& Computers, 36, 516-524.

Perry, C., Ziegler, J. C., \& Zorzi, M. (2007). Nested incremental modeling in the development of computational theories: The CDP+ model of reading aloud. Psychological Review, 114, 273-315.

Seidenberg, M. S., \& McClelland, J. L. (1989). A distributed, developmental model of word recognition and naming. Psychological Review, 96, 523-568.
Sirois, M., Kremin, H., \& Cohen, H. (2006). Picture-naming norms for Canadian French: Name agreement, familiarity, visual complexity, and age of acquisition. Behavior Research Methods, 38, 300-306.

Stadthagen-Gonzalez, H., \& Davis, C. J. (2006). The Bristol norms for age of acquisition, imageability, and familiarity. Behavior Research Methods, 38, 598-605.

Zevin, J. D., \& Seidenberg, M. S. (2002). Age of acquisition effects in word reading and other tasks. Journal of Memory \& Language, 47, 1-29.

Zevin, J. D., \& SeIDEnberG, M. S. (2004). Age-of-acquisition effects in reading aloud: Tests of cumulative frequency and frequency trajectory. Memory \& Cognition, 32, 31-38.

\section{ARCHIVED MATERIALS}

The following materials associated with this article may be accessed through the Psychonomic Society's Norms, Stimuli, and Data archive, www.psychonomic.org/archive.

To access these files, search the archive for this article using the journal name (Behavior Research Methods), the first author's name (Ferrand), and the publication year (2008).

FILE: Ferrand-BRM-2008.zip

DESCRIPTION: The compressed archive file contains two files:

Ferrand(2008).txt, containing AoA frequency and subject information. Ferrand(2008).xls, containing the above information in Excel spreadsheet format

AUTHOR'S E-MAIL ADDRESS: ludovic.ferrand@univ-bpclermont.fr.

(Manuscript received February 17, 2008; revision accepted for publication April 22, 2008.) 